UNIVERSITY OF WAIKATO

Hamilton

New Zealand

\title{
A Futures Market Reduces Bubbles but Allows Greater Profit for More Sophisticated Traders
}

Charles Noussair, Steven J. Tucker and Yilong Xu

\section{Department of Economics}

Working Paper in Economics 12/14

October 2014

Corresponding Author

Steven Tucker

Economics Department

University of Waikato

Private Bag 3105

Hamilton

New Zealand, 3240

Email: steven.tucker.nz@gmail.com
Charles Noussair \& Yilong Xu

Economics Department

Tilburg University

P.O. Box 90153

5000 LE Tilburg

The Netherlands

Email: c.n.noussair@uvt.nl

Email: y.xu@uvt.nl 


\begin{abstract}
We study the effect of the addition of a futures market, in which contracts maturing in the last period of the life of the asset can be traded. Our experiment has two treatments, one in which a spot market operates on its own, and a second treatment in which a spot and futures market are active simultaneously. We find that the futures market reduces spot market mispricing among a trader population prone to bubbles, while having no effect on mispricing in a group not prone to it. Thus, overall, futures markets aid price discovery in the spot market, although the futures markets themselves exhibit considerable overpricing. Individuals with higher cognitive reflection test (CRT) scores achieve greater earnings, as they tend to sell in the overpriced futures market, while traders with lower CRT score make purchases in the futures market. We also consider the predictive power of an enhanced CRT measure (ECRT), which weightstwo types of incorrect answers differently.
\end{abstract}

\title{
Keywords
}

asset market experiment market institution

futures market

\section{JEL Classification}

C91, G13

\section{Acknowledgements}

The authors are grateful to participants at the Experimental Finance Conference 2014 for helpful comments and suggestions. 


\section{Introduction}

Futures markets are thought to aid in the effective functioning of asset markets. For instance, $\operatorname{Cox}[1976]$ argues that the existence of futures markets may attract additional traders to participate in spot markets. Futures prices provide an aggregated measure of traders' expectations about prospective spot prices. Indeed, as Grossman [1.977] points out, in an imperfect market, it is impossible for a spot market itself to perfectly incorporate all information about the future such as traders' expectation about future prices. The futures market helps harmonize beliefs about future prices, which may in turn help price discovery in the spot market.

Empirically, how well futures markets aid price discovery may be reflected by the leadlag relationship between spot and futures markets. Garbade and Silber [1.983], estimate that about 75 percent of new information [is] incorporated in futures prices first. Chan [11992], among others, reports that futures market price indices tend to lead their counterpart spot

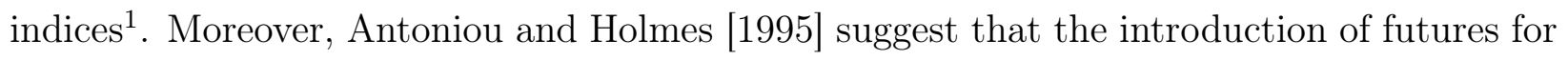
the FTSE-100 index has improved the functioning of the spot market.

The effects of futures markets on spot market price discovery have also been studied in controlled laboratory environments. In markets for short-lived (2- or 3-period) assets, it has been shown that the existence of a futures market significantly fosters information transmission among traders and thereby increases the convergence rate of prices to the rational expectations equilibrium level in the spot market (Forsythe et al. [1982]; Friedman et al. [1.984]). This suggests that a futures market creates common rational expectations about future prices for traders. This in turn leads spot markets to converge to rational expectations price levels.

In the paradigm of Smith et al. [1988], asset prices in experimental asset markets tend to exhibit a pattern of bubbles and crashes (see Palan [2013] for a recent overview) in the

\footnotetext{
${ }^{1}$ The intraday lead-lag relationship between index futures and spot prices has been studied with more advanced econometric techniques that allow for high frequency data, see e.g., de Jong and Nijman [11997].
} 
absence of futures markets. In this setting, the asset has a relatively long life, typically 15 periods. Each unit of the asset pays a per-unit dividend at the end of each period. The dividend distribution and process are common knowledge. Since the only source of intrinsic value for the asset is the dividends and the time horizon is finite, the fundamental value at any point in time can be calculated. The fundamental value declines over time by the amount of the expected per-period dividend, as the remaining number of dividend payments declines. However, instead of tracking fundamental values, market prices typically greatly exceed fundamental values for a prolonged period of time and then rapidly drop to fundamental value as the end of life of the asset approaches.

Will the presence of a futures market aid price discovery of long-lived asset traded in spot market? Porter and Smith [1995. consider the effects of the inclusion of a market for futures contracts maturing half-way through the life of the asset, namely in period eight of a 15-period horizon. They find that it exerts at best a very modest dampening effect on price bubbles. Noussair and Tucker [20066] find that the addition of a complete set of futures markets, one maturing in every period, serves to eliminate spot market price bubbles. However, they also observe widespread mispricing in the futures markets themselves. The research question we ask in this paper is how effective one futures market, for contracts maturing in the final period of the asset's life, is in reducing price bubbles. We conjecture that the futures market maturing in the last period might be especially important in improving price discovery because it encourages backward reasoning about the price path from the end of the life of the asset to the present. It also helps traders to form common expectations about futures prices.

Our experiment has two treatments, one in which a spot market operates on its own, and a second treatment in which a spot and futures market are active simultaneously. The experiment is conducted in two different locations: at Tilburg University in the Netherlands, and at University of Waikato in New Zealand. We conduct 25 sessions, of which 13 took place in New Zealand. A cognitive reflection test [Frederick, 2005], measuring ability/willingness 
to reflect on a logical problem, is administered to all participants in both locations before the market was introduced to them.

We obtain the following results. In the Waikato sample, futures markets reduce bubble magnitudes and overall mispricing significantly. In the Tilburg sample, characterized by considerably smaller bubbles when no futures market is present, the futures market does not affect mispricing. The average cognitive reflection test (CRT) score of a trader cohort is significantly negatively correlated with the magnitude of mispricing. This is especially true for baseline treatments. Individually, higher CRT scores are associated with greater earnings. In the futures markets, traders with relatively low CRT scores tend to make purchases at prices greater than the rational expectations equilibrium level. Traders with relatively high CRT scores tend to make sales, which are highly profitable, in these overpriced futures markets. The main conclusion of our study is that one futures market, for contracts maturing in the last period of the life of the asset, reduces mispricing among a population prone to bubbles, while having no effect on mispricing in a group not prone to them. Thus, overall, futures markets aid price discovery.

The rest of the paper is organized as follows: Section $\square$ outlines the experimental design and procedures. Section 3 presents results from the experiment, and Section $⿴ 囗 十$ concludes.

\section{Experimental Design and Procedures}

\subsection{The Baseline Treatment}

In the sessions of the Baseline treatment, participants can trade an asset with a life of 15 periods. At the end of each period, the asset pays a dividend that is independently drawn in each period from a four-point distribution in which each unit of asset pays a dividend of 0 , 8, 28, and 60 francs (experimental currency used for trade) with equal probability. To rule out any effect of the arrival sequence of dividend stream on asset prices, we use computer to generate a sequence of dividend payments and the same sequence was used for all sessions. 
Dividends are the only source of value for the asset. The fundamental value of each unit of asset during period $t$ equals the expected future dividend stream to be received, which is $24 *(16-t)$ francs.

At the beginning of the experiment, participants are endowed with 3,600 francs as well as 10 units of asset. Therefore, the cash to asset ratio at the opening of the market is

equal to one $\left(=\frac{3600}{24 * 15 * 10}\right)$. In all treatments, short selling and borrowing cash for purchases is not allowed. The exchange rate in our experiment is either 460 francs $=1$ euro or 275 francs $=1 \mathrm{NZ}$ dollar, depending on the location. The continuous double auction market is computerized by using z-Tree [Fischbacher, [2007]].

\subsection{Futures Market Treatment}

In the Futures treatment, a futures market is operating in addition to the spot market. Futures contracts are realized in period 15. The difference between the two markets is that the actual trade does not take place immediately in the futures market, whereas it does in the spot market. In other words, a trader who makes a contract in the futures market to buy (sell) a unit of asset is committed to buy (sell) the unit at the beginning of the fifteenth period. If a trader had committed to sell a unit of the asset in the futures market, she continued to receive the dividends on the unit until the trade took effect. The buyer who had committed to buy this unit would only receive a one time dividend payment at the end of the fifteenth period given that they do not sell the unit in the last period. Therefore, the rational expectations equilibrium price in the futures market equals 24 francs. In our experiment, the futures market opens 3 minutes prior to the opening of the spot market. The futures market remains open until the end of spot market period 14 .

Due to the presence of the futures market and restriction of no short selling, there could be a difference between what we call the "available stock" and the "actual stock" of asset. These two would be different if an agent makes commitments in the futures market. The available stock for sale in the futures market is the sum of the actual stock in an agent's inventory 
plus the net amount contracted in the futures market, which (the latter) is the difference between contracted purchases minus contracted sales in the futures markets. The available stock for sale in the spot market never exceeds the actual stock because the contracted purchase only enters one's inventory at the beginning of the last period. All these constraints guarantee that all the commitments made in the futures market are executable when the time comes. In addition, those assets that have been already committed to sell in the futures market cannot be sold again in the spot market. All the above mentioned constraints are automatically implemented or calculated by the computer and are clearly explained in detail to the participants ${ }^{\llbracket}$.

\subsection{Procedures}

A total of 25 sessions were conducted between June 2013 and February 2014. Of these, 13 sessions ( 7 baseline sessions and 6 treatment sessions) were run at the Waikato Experimental Economics Laboratory at the University of Waikato in New Zealand and 12 sessions (6 baseline sessions and 6 treatment sessions) were conducted at the CentERlab at Tilburg University in the Netherlands. The experimenters strictly followed the same procedures in all sessions.

There were 9 traders participating in most sessions, with a few sessions with less people due to absenteeism. Participants were university students from a variety of majors who had no previous experience on asset market experiments. Upon arrival, subjects were free to choose a computer desk to use for the session.

A session proceeded as follows. (1) Subjects had three minutes to finish the cognitive reflection test developed by Frederick [2005]. The test consists of three questions assessing individuals' ability/willingness to suppress an intuitive and spontaneous wrong answer in favor of a reflective and deliberative right answer. A subject receives one euro or two NZ dollars for each correct answer in NL and NZ respectively. (2) Subjects were then allocated

\footnotetext{
${ }^{2}$ The experiment instructions are provided in the Appendix
} 
15 minutes to read the instructions for the asset market on their own. They were strongly encouraged to raise any questions when reading the instructions, which were privately addressed. (3) The experimenter summarized all of the main features of the market experiment on an overhead projector. (4) Subjects were asked to finish the quiz and the experimenter would then check each one's answer privately. If a subject made any incorrect responses, the correct answers were given and explained privately to the individual. (5) Upon completion of reviewing all subjects' quiz answers, a 3-minute practice period was conducted. For the futures treatment, the futures market opened simultaneously with the spot market in the practice period. Earnings in the practice period did not count toward final earnings. (6) Asset and cash endowments were re-initialized and the markets were started. Subjects were encouraged, but not required, to keep track of their holdings and earnings at the end of each period. Subjects received 20 euro or 32 NZ dollars on average (depending upon location) at the end of the experiment, including earnings from their CRT responses.

\section{Results}

\subsection{Overall Results}

The time series of average transaction prices for both the spot market and the futures market are plotted in Figure $\square$. The horizontal axis indicates the period and the vertical axis shows the average transaction price. In the Baseline treatment, where no futures market is available, the pooled average transaction prices are above fundamental value from period 6 onward. In comparison, the pooled average transaction prices in the spot market of the Futures treatment (denoted as Pooled Avg Spot) track the fundamental value much more closely. Moreover, the average transaction prices in the pooled futures spot market are lower than the Baseline treatment in every period. In the futures market, the average transaction prices are initially greater than the rational expectations equilibrium price and gradually converge to that price towards the end of the market. 


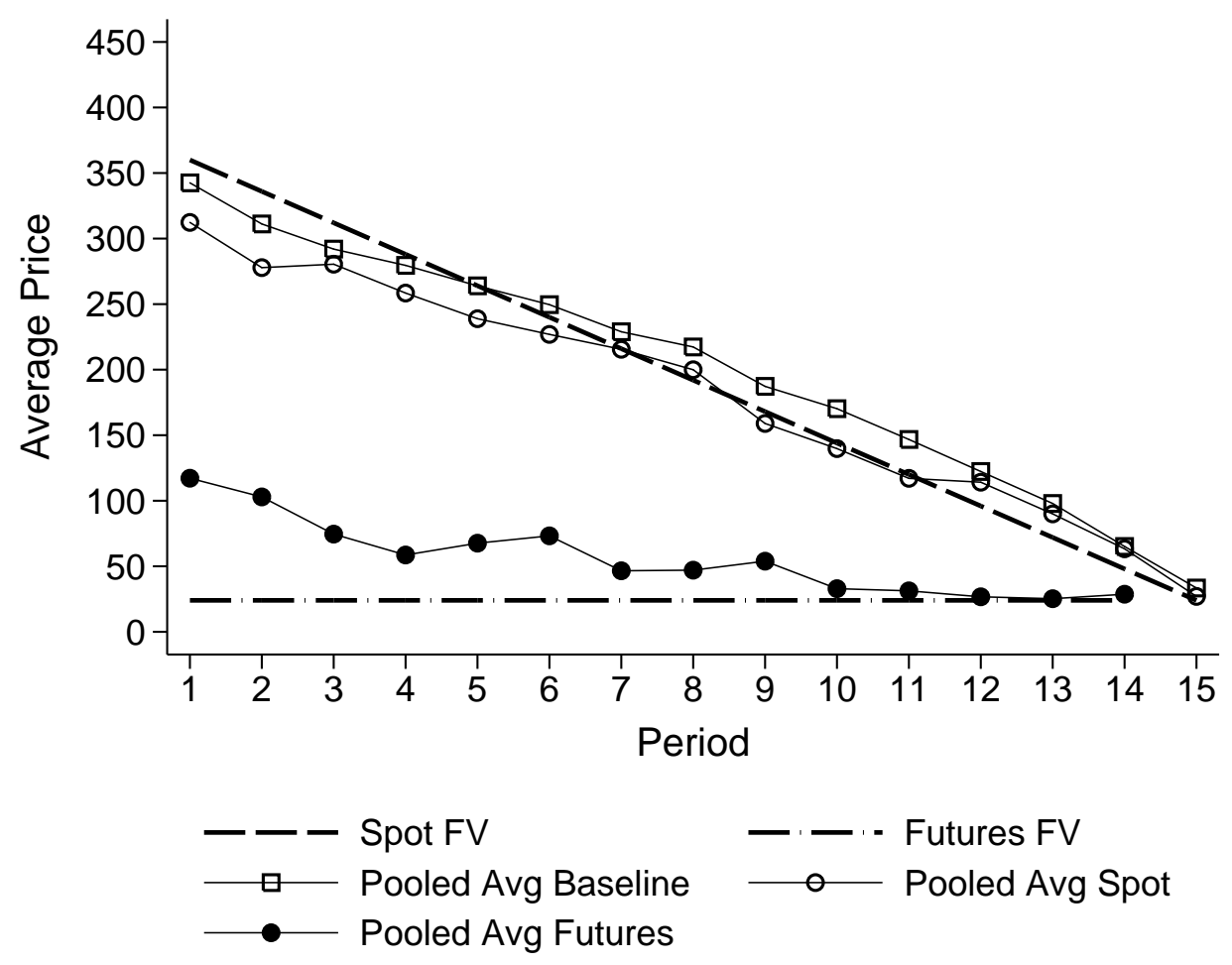

Figure 1: Time series of average transaction price, pooled data (25 sessions).

Figure 2 shows the average transaction prices for each treatment based upon location. The average transaction prices in the Baseline treatment initially start at similar values in the two locations. However, from period 2 on, the prices in NZ are above those in NL and above the fundamental value from period 5 onward. In comparison, the average transaction prices in NL converge towards the fundamental value till period 7 upon which they follow the fundamental value closely from then onwards. In contrast, the average price paths in both the futures and spot markets are very similar in the Futures treatment between the two locations.

The following subsections are organized as follows. We first introduce the bubble measures we employ in this study. We then report on the the effect of the existence of a futures market on spot market behavior in each of the two data collection locations. Lastly, we study the relationship between CRT scores and market, as well as individual, outcomes. 

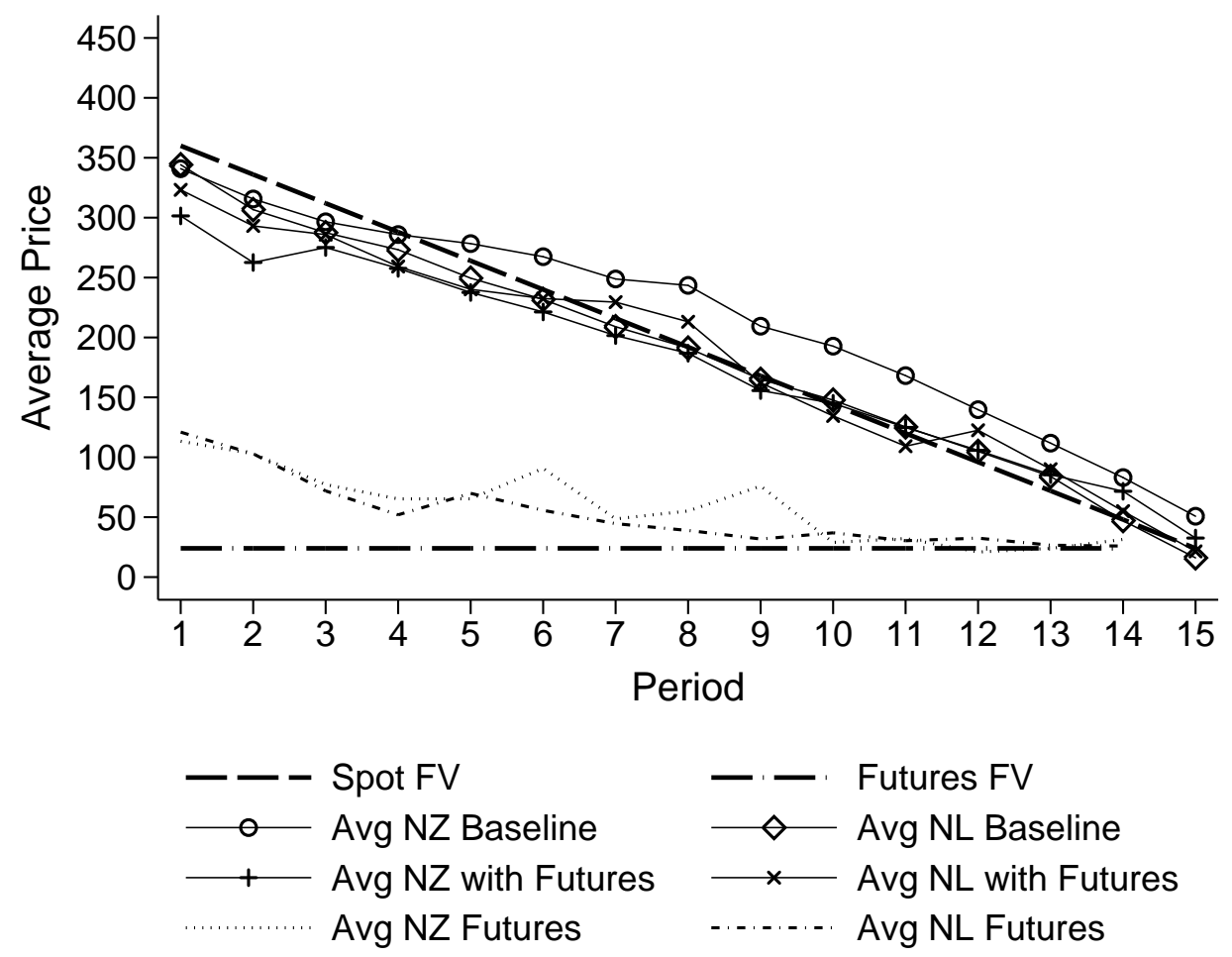

Figure 2: Time series of average transaction price for each location.

\subsection{Bubble Measures}

The three measures we use to compare bubble magnitudes in this are Relative Absolute Deviation (RAD), Relative Deviation (RD), and Turnover ${ }^{\text {I. }}$.

RAD is a measure of absolute difference between price and fundamental value, while $\mathbf{R D}$ is a measure of the difference between the price level and fundamental value [Stöckl] et al, [2010]. RAD measures how closely prices track fundamental value, while RD indicates whether on average prices are above $(\mathrm{RD}>0)$ or below $(\mathrm{RD}<0)$ fundamental value.

Turnover (Van Boening et al. [199:3]) is the total number of transactions over the life

\footnotetext{
${ }^{3} \mathrm{RAD}$ is defined as $\frac{1}{T} \sum_{t=1}^{T}\left|\overline{P_{t}}-F V_{t}\right| /\left(\sum_{t=1}^{T} F V_{t} / T\right)$, where $p$ denotes period and $T$ stands for the total number of periods. $F V_{t}$ is the fundamental value in period $t$ and the term $\overline{P_{t}}$ denotes the (volume-weighted) average price. Since our trading rules did not allow batch orders, $\overline{P_{t}}$, for the purpose of this paper, boils down to the average price in period $t$. The measure RD is the same as RAD, except that the numerator does not include the absolute value operator. Specifically, $\mathrm{RD}$ is expressed as $\frac{1}{T} \sum_{t=1}^{T}\left(\overline{P_{t}}-F V_{t}\right) /\left(\sum_{t=1}^{T} F V_{t} / T\right)$. Turnover is a normalized measure of the amount of trading activity over the course of the asset life, which is defined as Turnover $=\left(\Sigma_{t} q_{t}\right) / T S U$, where $q_{t}$ is the quantity of units of the asset exchanged in period $\mathrm{t}$ and TSU is equal to the total stock of units (in our case, it is 90 units).
} 
of the asset divided by the total stock of units in the market. A high Turnover indicates a high volume of trade, which in experimental markets of the type studied here, is typically associated with mispricing possibly due to either heterogeneous expectations or errors in decision making which prompts trade.

Table 1: Session Average Bubble Measures for Each Location

\begin{tabular}{lrrrrr}
\hline & \multicolumn{2}{c}{ New Zealand } & & \multicolumn{2}{c}{ The Netherlands } \\
\cline { 2 - 3 } \cline { 5 - 6 } & Baseline & Futures & & Baseline & Futures \\
\hline RAD & 0.23 & 0.16 & & 0.10 & 0.22 \\
RD & 0.12 & -0.08 & & -0.03 & -0.01 \\
Turnover & 3.37 & 2.85 & & 3.75 & 1.96 \\
\hline
\end{tabular}

Table $\mathbb{T}$ summarizes the session average of the three bubble measures that we employed in this paper.

\subsection{The New Zealand Sessions}

Figures 3 and $⿴ 囗 十$ illustrate the time series of average transaction prices in the Baseline and Futures treatments respectively for each session conducted in NZ. The spot market price trajectories are represented by dashed lines and futures market price trajectories are represented by dotted lines. In the Baseline treatment, where no futures market is available, the assets are typically overvalued in the NZ sessions. In the Futures treatment, contracts in the futures market are initially overvalued on average, but converge to the rational expectations price level by period 9 and follow from then onward. The effects of the futures market on the spot market is clearly visible by comparing the average transaction price between the two treatments in Figures 3 and $⿴$. On average, the spot market prices are lower when a futures market is present than when it is not.

A Mann-Whitney-Wilcoxon test, for the bubble measure RD, confirms this observation with p-value lower than $5 \%$. Table $\rrbracket$ summarizes the results of Mann-Whitney tests comparing the bubble measures between the Baseline and Futures treatments for the NZ sample. 

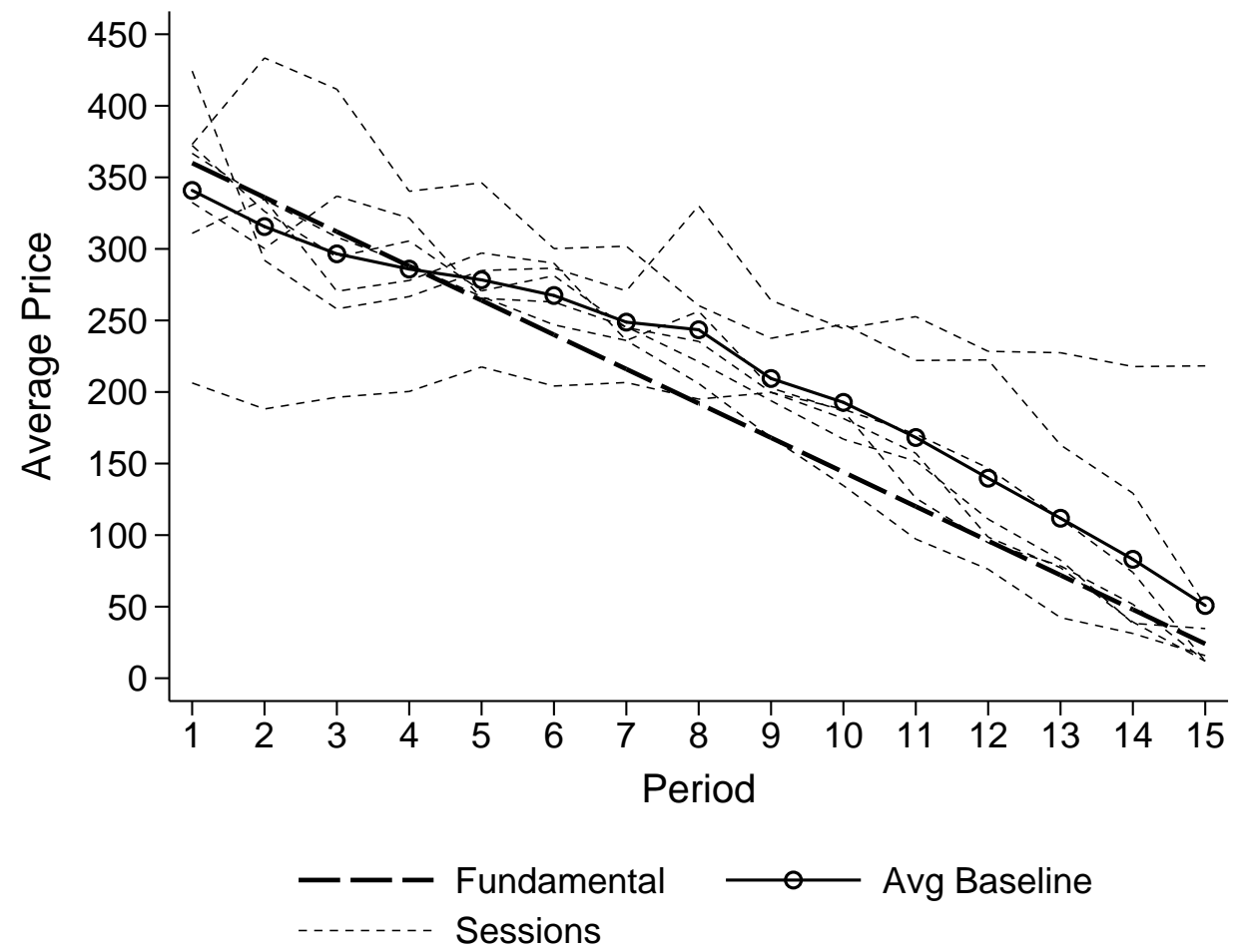

Figure 3: Time series of average transaction price of the baseline sessions, New Zealand

A positive z-score for $\mathrm{RAD}$ and $\mathrm{RD}$ means prices generally adhere more closely to fundamental value in the Futures treatment than in the Baseline treatment. A positive z-score for Turnover means the turnover in the Futures treatment spot market is smaller than that in the Baseline.

Table 2: Mann-Whitney-Wilcoxon Test for Bubble Measures

\begin{tabular}{|c|c|c|c|c|c|c|}
\hline \multirow{2}{*}{ Measures } & \multicolumn{2}{|c|}{ New Zealand $(\mathrm{N}=13)$} & \multicolumn{2}{|c|}{ The Netherlands $(\mathrm{N}=12)$} & \multicolumn{2}{|c|}{ Pooled $(\mathrm{N}=25)$} \\
\hline & Z-score & p-value & Z-score & p-value & Z-score & $\mathrm{p}$-value \\
\hline RAD & 0.714 & 0.4751 & -1.441 & 0.1495 & -0.761 & 0.4464 \\
\hline $\mathrm{RD}$ & $2.143^{* *}$ & 0.0321 & 0 & 1.0000 & $1.741^{*}$ & 0.0818 \\
\hline Turnover & $2.000^{* *}$ & 0.0455 & $1.922^{* *}$ & 0.0547 & $2.938^{* * *}$ & 0.0033 \\
\hline
\end{tabular}

Note: ${ }^{*}$ significant at $10 \% ;{ }^{*}$ significant at $5 \% ;{ }^{* * *}$ significant at $1 \%$. 


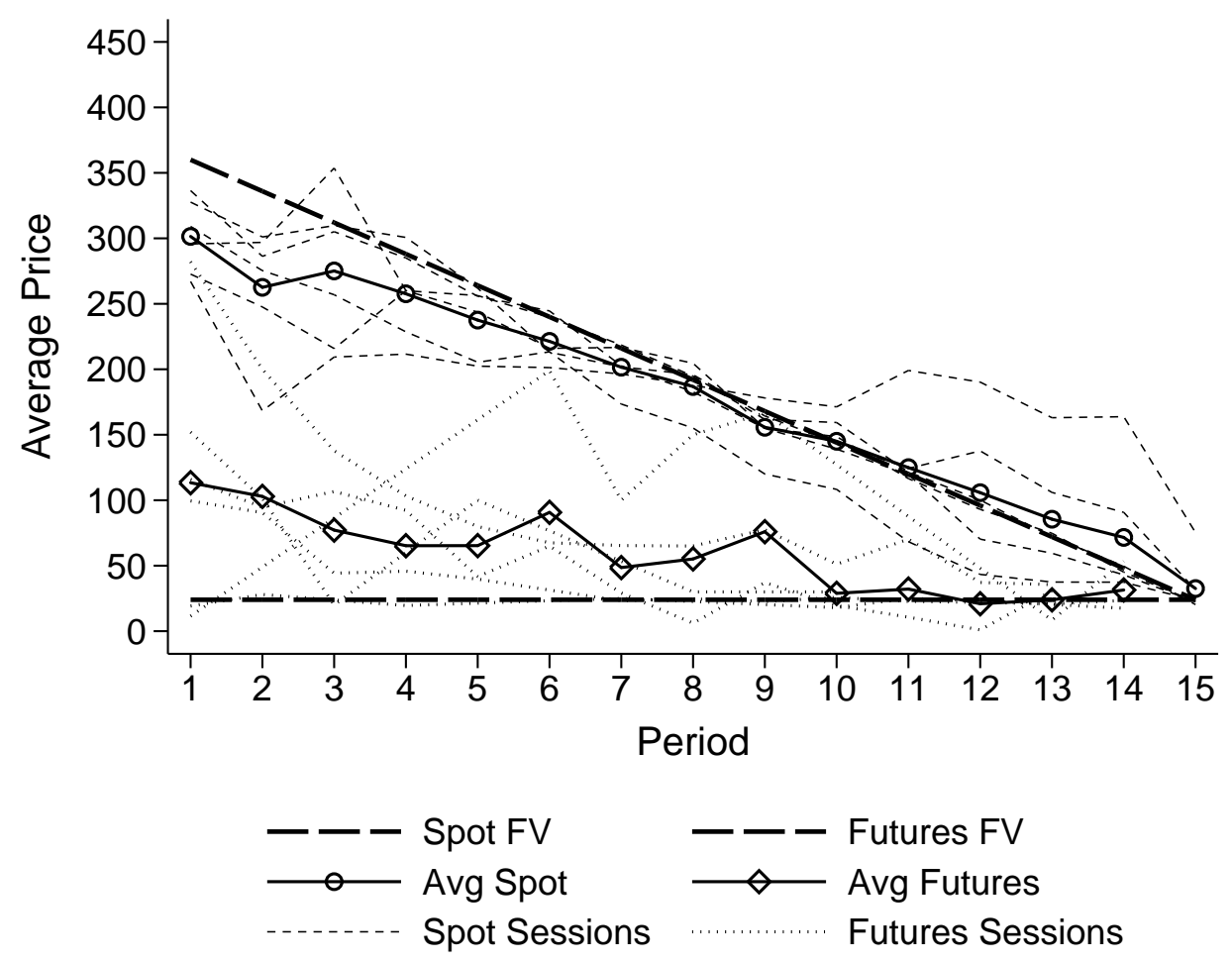

Figure 4: Time series of average transaction price of the Futures sessions, New Zealand

\subsection{The Netherlands Sessions}

Figure 5 and Figure 6 present the time series of average transaction prices in the Baseline and Futures treatments respectively for each session conducted in the Netherlands(NL). Once again, the spot market price trajectories are represented by dashed lines and futures market price trajectories are represented by dotted lines. The average transaction prices in the Baseline treatment follow the fundamental value very well. This is in contrast to the price bubble observed in the NZ baseline data. The spot market average transaction prices in the Futures treatment conducted in NL also track the fundamental value closely. The summary of the Mann-Whitney-Wilcoxon test results presented in Table $\nabla$ confirms these observations of the NL data as none of the p-values are critical. These results imply that there is no significant effect of the presence of a futures market on spot market prices in general within the NL sample. However, this is predominantly due to the absence of a bubble 
in the NL baseline data and thus there is no room for improvement in reducing mispricing ${ }^{\text {II }}$. Alternatively, we find that the presence of a futures market does not induce price bubbles in environments that are not prone to bubble formation.

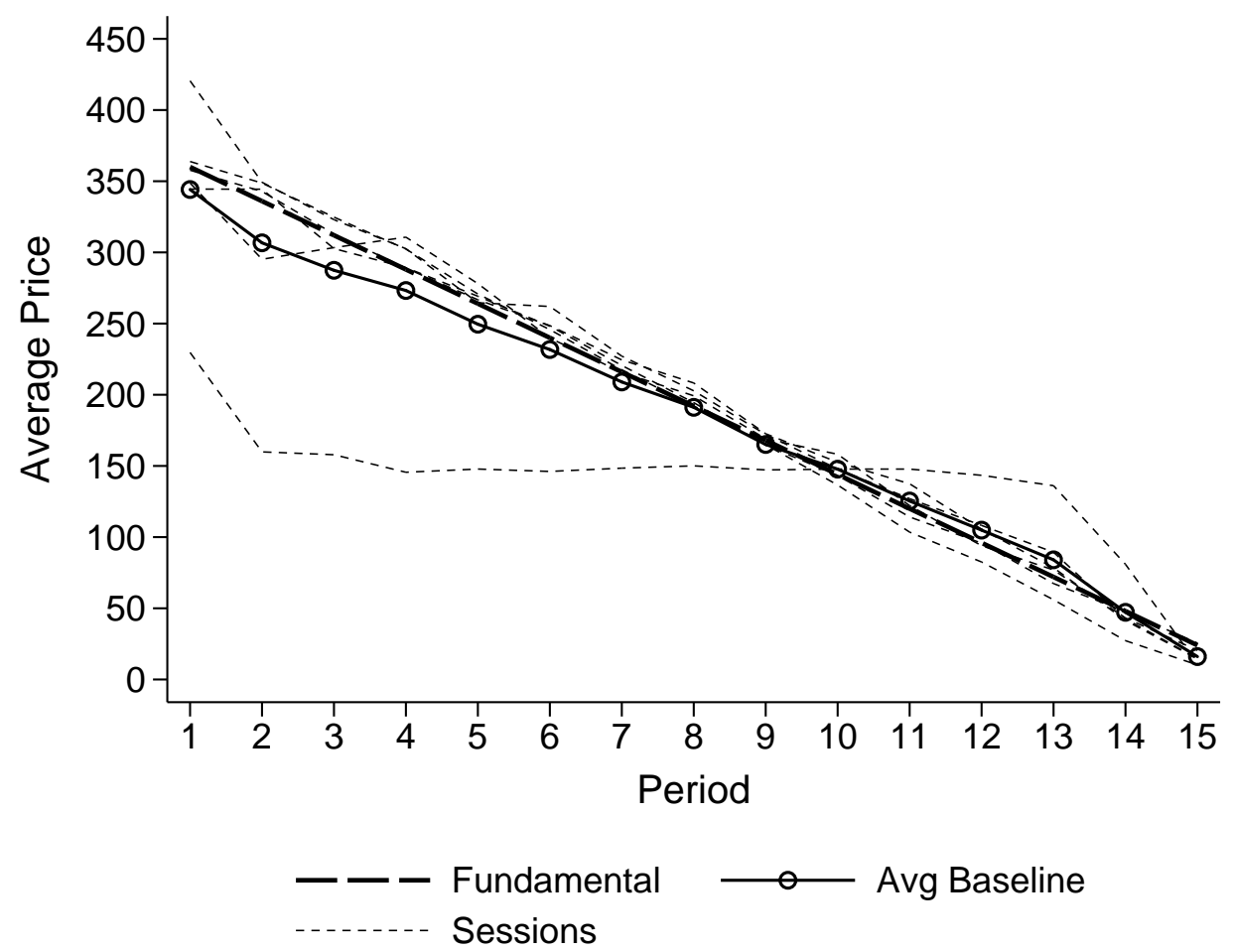

Figure 5: Time series of average transaction price of baseline sessions, the Netherlands

\subsection{Analysis of the Pooled Data}

For the pooled data from both locations (25 sessions), a Mann-Whitney-test, also reported in Table 2 , indicates that the futures market has a borderline significant attenuating effect on asset price bubbles, with RD being significantly lower in the Futures treatment $(\mathrm{p}$-value $=0.0818)$. In addition, turnover is also significantly lower in Futures than that in the Baseline $(p$-value $=0.0033)$, suggesting that the futures market does indeed help induce common expectations about future prices.

\footnotetext{
${ }^{4}$ The Mann-Whitney-Wilcoxon test suggests, for the baseline sessions, that the bubble measure RAD for NZ is significantly larger than that for the NL sample, with $\mathrm{p}$-value $=0.03$. The result for RD and Turnover is qualitatively the same, though not significant.
} 


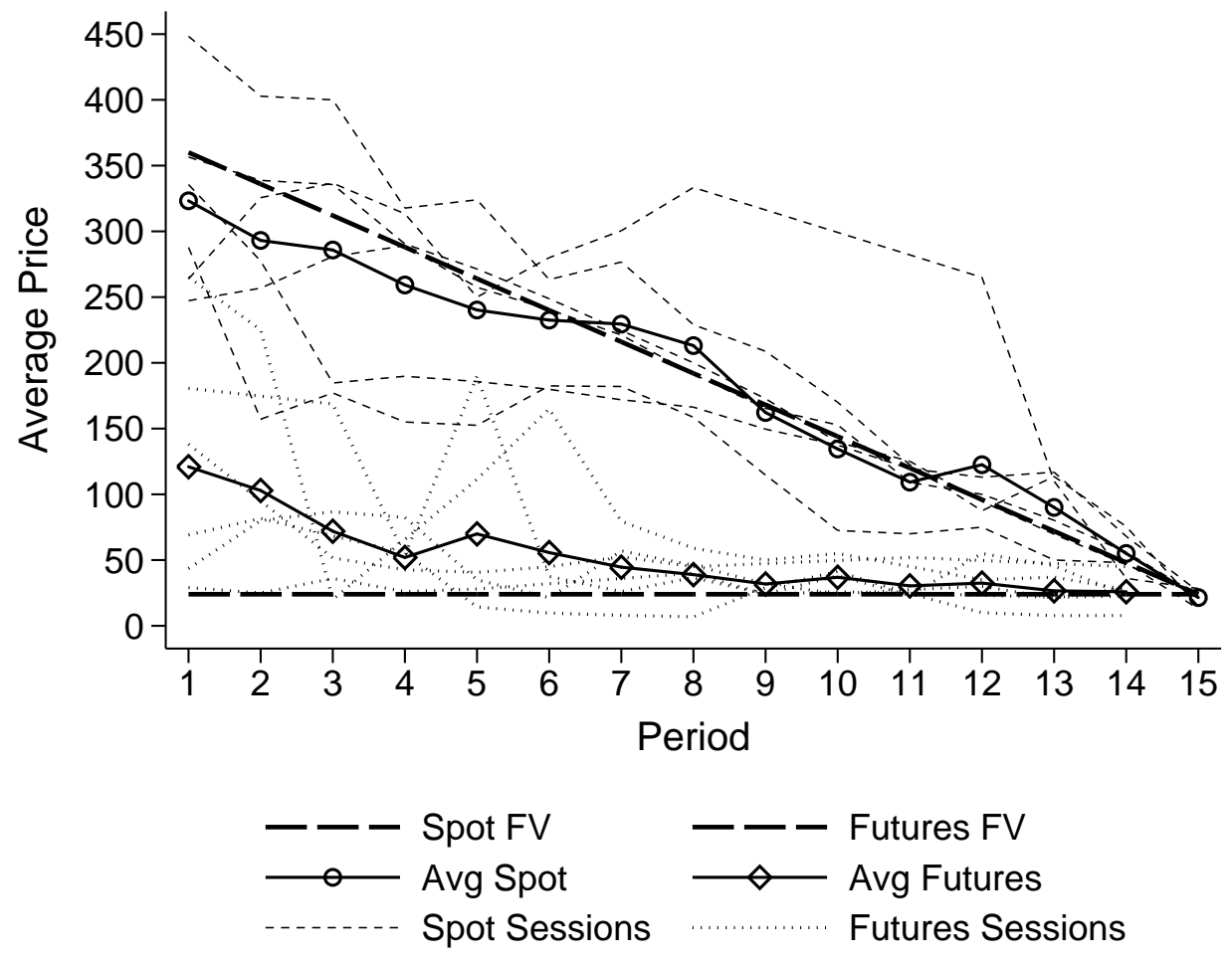

Figure 6: Time series of average transaction price of the Futures sessions, the Netherlands

We therefore conclude that a futures market, for contracts maturing in the last period of the life of the asset, reduces mispricing among a population prone to bubbles, while having no effect on mispricing in a group not prone to bubbles. It has an attenuating effect on asset price bubbles overall.

\subsection{The Role of CRT}

In this section, we study the relationship between average CRT among traders in a session and pricing accuracy, as well as between CRT and profit at the individual level. The average CRT score in a trader cohort may be related to accurate pricing because agents who are more willing to or capable of think hard on logical problems may also be less prone to decision

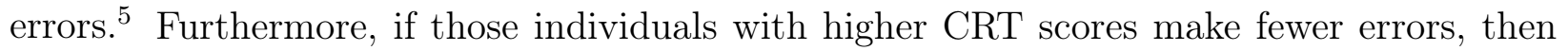

\footnotetext{
${ }^{5} \mathrm{CRT}$ score is significantly correlated with cognitive ability, as measured with other instruments. Frederlick [20015] reports a correlation of 0.44 between CRT performance and SAT score as well as a 0.43 correlation between CRT scores and the results of the Wonderlic IQ test.
} 
CRT scores and earnings would have a positive correlation $^{\mathbf{t}}$.

The CRT questions are designed in such a way that there exists an intuitive and spontaneous wrong answer for each of them. In calculating the CRT score, each correct answer earns one point and all incorrect answers earn zero points. Therefore, the possible distribution of scores ranges from 0 to 3 .

\subsubsection{The Enhanced CRT (ECRT)}

In the conventional calculation of CRT, all incorrect answers count zero towards the overall score regardless of the type of error. Incorrect answers may be divided into two categories, (a) an unique intuitive but spontaneous answer that indicates the ability to calculate, but does not reflect the proper reasoning required to solve the problem, or (b) all other answers ${ }^{\text {D. }}$. Answers of type (a) reflect a different process of reasoning than those of class (b). Those who give intuitive/spontaneous wrong answers are those who in a sense have been tricked by the questions. Being tricked may reflect a number of forces, such as cognitive limitations or overconfidence about being able to quickly arrive at the answer without detailed reflection. Mistakes of type (b) may reflect even more serious cognitive limitations or even greater unwillingness to reflect on the question at hand. On the other hand, they may reveal that the respondent is not overconfident and/or easily induced into giving the trick answer.

In this paper, we propose a new CRT measure called enhanced CRT $(\mathrm{ECRT})^{\mathbb{8}}$ It punishes errors of type (a) more severely than those of type (b). It is meant to provide a measure that places more weight on those who can be tricked because they answer questions impulsively. Errors of type (a) count -1 toward the overall CRT score while errors of type (b) count 0 .

\footnotetext{
${ }^{6}$ The CRT questionnaire is presented in the Appendix.

${ }^{7}$ The correct answers to the three CRT questions are (5,5, and 47) while the intuitive/spontaneous incorrect answers are $(10,100$, and 24$)$

${ }^{8}$ We have also constructed a measure called ECRT2 which punishes type (b) errors more strongly than those of type (a). Type (a) errors count -1 while type (b) errors count 0 toward an individual's overall score. Therefore, the possible range of ECRT2 scores is from -3 to 3 . In the following analysis, we report both conventional CRT as well as ECRT.
} 
Table 3: Overview of three CRT measures, grouped by locations

\begin{tabular}{lrrrrrrr}
\hline & \multicolumn{3}{c}{ New Zealand $(\mathrm{N}=113)$} & & \multicolumn{3}{c}{ The Netherlands (N=103) } \\
\cline { 2 - 5 } \cline { 8 - 9 } & Baseline & Futures & Overall & & Baseline & Futures & Overall \\
\hline Average CRT & 1.05 & 1.44 & 1.24 & & 1.83 & 1.76 & 1.80 \\
Average ECRT & -0.53 & 0.15 & -0.20 & & 0.98 & 0.86 & 0.92 \\
Number of Zeros $(\mathrm{CRT}=0)$ & 25.00 & 16.00 & 41.00 & & 10.00 & 10.00 & 20.00 \\
\hline
\end{tabular}

The range of possible total ECRT scores on the three question task is from -3 to 3 . The average ECRT score over all 25 sessions is 0.33 while the conventional CRT average is 1.51 . About $39 \%$ of agents gave at least one answer that is a mistake of type (a). In addition, in our analysis, we consider a third modified measure of conventional CRT, i.e. the number of subjects with CRT $=0$ (hereafter called "zeros") in which a subject answers all questions incorrectly irrespective of the type of incorrect answer.

An overview of (E)CRT measures as per each location is provided in Table [3. Subjects' level of sophistication in NL and NZ seems to be quite different. Specifically, for the measure zeros, there are $20 \%$ of subjects who have $\mathrm{CRT}=0$. This value is almost doubled in NZ: $36 \%$ of subjects failed to give any correct answer. For the measure ECRT, $24 \%$ of subjects have ECRT $<0$ in NL, whereas in NZ, $50 \%$ of subjects have ECRT $<0$.

\subsubsection{CRT and Market Behavior}

Table 1 below summarizes the Spearman correlation coefficients between the ECRT scores, the conventional CRT scores and the spot market bubble measures. We find that a higher average (E)CRT score in a session is typically associated with lower RAD values in the Baseline treatment. The ECRT score exhibits a stronger correlation with pricing accuracy than the traditional CRT measure. Moreover, the CRT variable is uncorrelated with pricing accuracy of the spot markets in the Futures treatment, while the ECRT score is positively correlated with the spot market bubble measures. The existence of futures markets, and thus more complicated environments, where futures markets are available, creates an opportunity 
Table 4: Spearman correlation coefficients between CRT performance and bubble measures

\begin{tabular}{|c|c|c|c|c|c|c|c|c|c|}
\hline & \multicolumn{3}{|c|}{ Baseline Treatment } & \multicolumn{3}{|c|}{ Futures Treatment } & \multicolumn{3}{|c|}{ All sessions } \\
\hline & CRT & ECRT & Zeros & CRT & ECRT & Zeros & CRT & ECRT & Zeros \\
\hline RAD & $\begin{array}{l}-\mathbf{0 . 7 4 7 6} \mathbf{6}^{* * * *} \\
(0.0033)\end{array}$ & $\begin{array}{l}-\mathbf{0 . 7 5 2 7} 7^{* * *} \\
(0.0030)\end{array}$ & $\begin{array}{l}\mathbf{0 . 8 3 3 3}^{\text {**** }} \\
(0.0004)\end{array}$ & $\begin{array}{l}0.3480 \\
(0.2677)\end{array}$ & $\begin{array}{l}\mathbf{0 . 5 7 2 9} * \\
(0.0515)\end{array}$ & $\begin{array}{l}0.1988 \\
(0.5357)\end{array}$ & $\begin{array}{l}-0.3203 \\
(0.1186)\end{array}$ & $\begin{array}{l}-0.2925 \\
(0.1560)\end{array}$ & $\begin{array}{l}\mathbf{0 . 6 0 7 3}^{\text {*** }} \\
(0.0013)\end{array}$ \\
\hline $\mathrm{RD}$ & $\begin{array}{l}-0.2510 \\
(0.4081)\end{array}$ & $\begin{array}{l}-0.3956 \\
(0.1809)\end{array}$ & $\begin{array}{l}0.4308 \\
(0.1417)\end{array}$ & $\begin{array}{l}0.2707 \\
(0.3949)\end{array}$ & $\begin{array}{l}0.2109 \\
(0.5106)\end{array}$ & $\begin{array}{l}-0.0515 \\
(0.8736)\end{array}$ & $\begin{array}{l}0.0093 \\
(0.9650)\end{array}$ & $\begin{array}{l}-0.0262 \\
(0.9011)\end{array}$ & $\begin{array}{l}0.1472 \\
(0.4825)\end{array}$ \\
\hline Turnover & $\begin{array}{l}-0.1989 \\
(0.5148)\end{array}$ & $\begin{array}{l}-0.2696 \\
(0.3731)\end{array}$ & $\begin{array}{l}0.2327 \\
(0.4442)\end{array}$ & $\begin{array}{l}-0.3199 \\
(0.3108)\end{array}$ & $\begin{array}{l}-0.2004 \\
(0.5324)\end{array}$ & $\begin{array}{l}-0.1988 \\
(0.5357)\end{array}$ & $\begin{array}{l}-0.2825 \\
(0.1712)\end{array}$ & $\begin{array}{l}-0.1815 \\
(0.3851)\end{array}$ & $\begin{array}{l}0.0826 \\
(0.6946)\end{array}$ \\
\hline
\end{tabular}

Note: CRT: average CRT score in a session. Zeros: Number of agents with CRT $=0$.

The p-values are in parenthesis.

$*$ significant at $10 \% ; * *$ significant at $5 \% ; * * *$ significant at $1 \%$.

for relatively sophisticated traders to speculate and to take advantage of those who are less sophisticated. This possibility is explored in the next subsection.

Moreover, we find that the number of subjects with $\mathrm{CRT}=0$ (or ECRT $\leq 0$ ) in a session is a better predictor of pricing accuracy than the average CRT score of the group ${ }^{\mathbf{g}}$. The correlation coefficient between the number of zeros and the RAD is typically more significant and stronger in magnitude than those between average CRT and the RAD. In addition, for the pooled data from all sessions, the more subjects with $\mathrm{CRT}=0$ in a session, the more prices deviate from the FV and the more volatile the prices are.

\subsubsection{The Relationship between (E)CRT and Profit at Individual Level}

The average prices in the futures markets are approximately five times the rational expectation price at the outset of the market. This provides an opportunity for more sophisticated traders to take advantage of the less sophisticated by selling futures contracts to them at excessively high prices.

Using the CRT and ECRT score as proxies for trader sophistication, we can test for whether this occurred in our markets. We analyze the relationship between an individual's

\footnotetext{
${ }^{9}$ We can also consider the number of participants who answered all three questions correctly. The Spearman rho between the number of individuals with a CRT score of 3 and RAD in the Baseline sessions is -0.5957 $(\mathrm{p}$-value $=0.0317)$, suggesting that a market with more sophisticated traders prices more accurately relative to the fundamental value. However, the other bubble measures, RD and Turnover, are not significantly correlated with the number of traders with the number of subjects with maximum CRT score.
} 

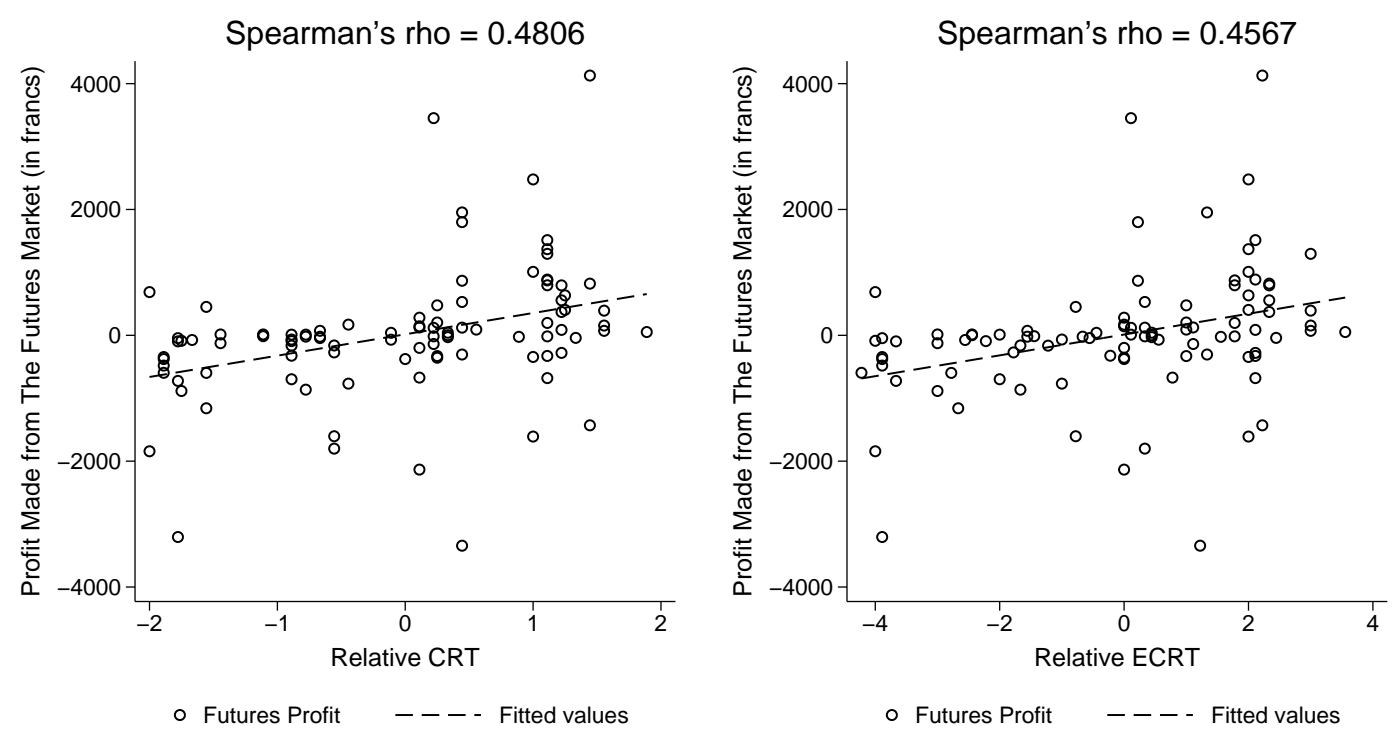

Figure 7: Relative (E)CRT Scores and Profit in the Futures Market

(E)CRT score relative to the market average ${ }^{\square}$ and her profit from trading in the futures market. The part of the individual's profit that is derived from her activity in the futures market is calculated as the sum of profit from selling and profit from purchasing ${ }^{\text {m. As can }}$ be seen in Figure $\mathbf{Z}$, our data suggest a strong and a significant (p-value $=0.0000$ for both CRT and ECRT) correlation between an individual's relative (E)CRT score and her profit from trading in the futures market.

We also investigate the relationship between the (E)CRT score and total overall earnings at the end of each session. This reflects profits earned in the spot market, and where applicable, the futures market as well. Overall, we find that individuals with relatively higher (E)CRT scores earn greater overall profit (Spearman's rho $=0.4729$, p-value $=0.0000$ for ECRT), see Figure 8 , in which the vertical axis reports the total profit of individuals and the horizontal axis is the relative (E)CRT score.

\footnotetext{
${ }^{10}$ For instance, a relative CRT of 1.5 means that the individual's CRT score is 1.5 points greater than the average in her cohort.

${ }^{11}$ It is calculated as (Avg Selling Price - 24)*number of units sold $+(24-\text { Avg Purchasing price })^{*}$ number of units bought, where 24 is the fundamental value of the asset traded in futures market. The result of "Avg Selling Price - 24" or "24 - Avg Purchasing price" is the profit per unit of assets sold (bought).
} 

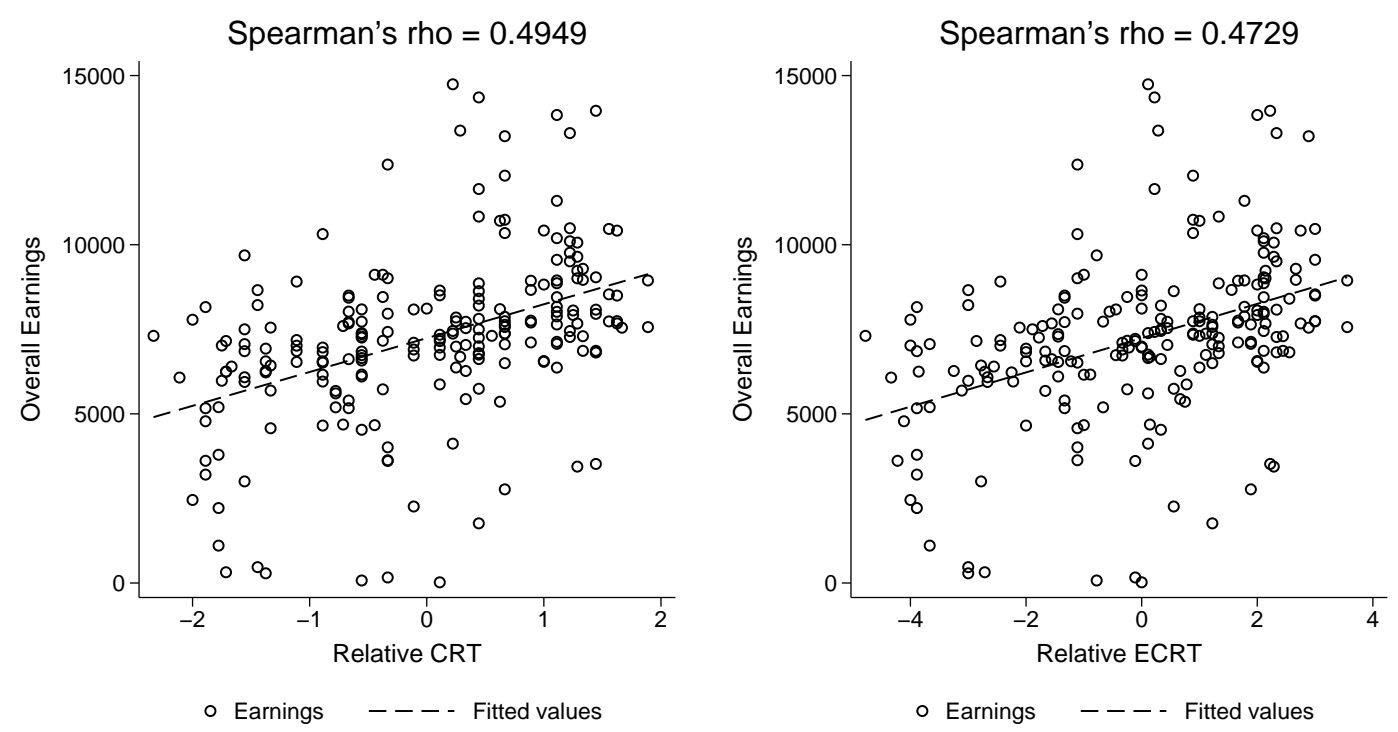

Figure 8: The (E)CRT score and final profit (in francs), pooled data

The relationship between (E)CRT score and overall profit is even stronger in sessions with a futures market than without one. Specifically, we find a 0.4207 (Spearman) correlation between relative ECRT and total profit in the Baseline treatment and a 0.5030 correlation in the Futures treatment (both with $\mathrm{p}$-value $=0.0000)$. The results for CRT correlates are qualitatively the same. The relationships between (E)CRT and overall profit by treatment are presented in Figure 9. Clearly, the relationship between (E)CRT score and profit is steeper in the Futures treatment. This result suggests that environments that are more demanding and complex, such as our Futures treatment, are more conducive to sophisticated traders earning more at the expense of the less sophisticated.

\subsubsection{The (E)CRT Scores and Trading Behaviors in the Futures Market}

Here, we consider how the behavior of low-and high-CRT scoring individuals differs in the futures market. Consider an individual who falls prey to the illusion that he makes a profit whenever he makes a purchase at a lower price than that at which he makes a sale. This individual might in period 1, for example, make a purchase in the futures market for 

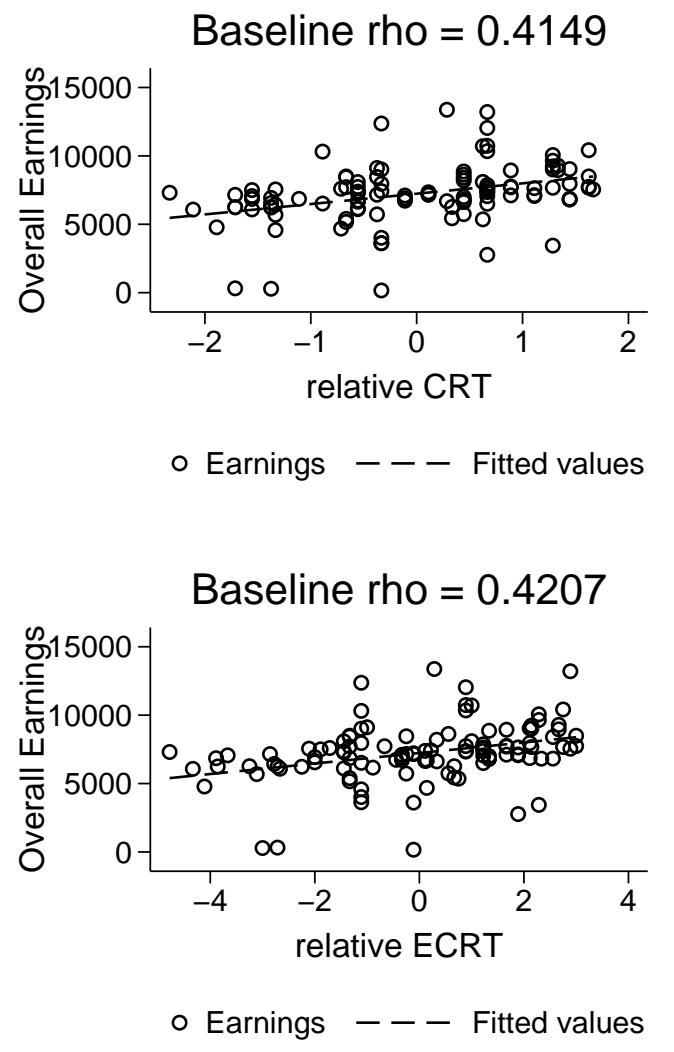

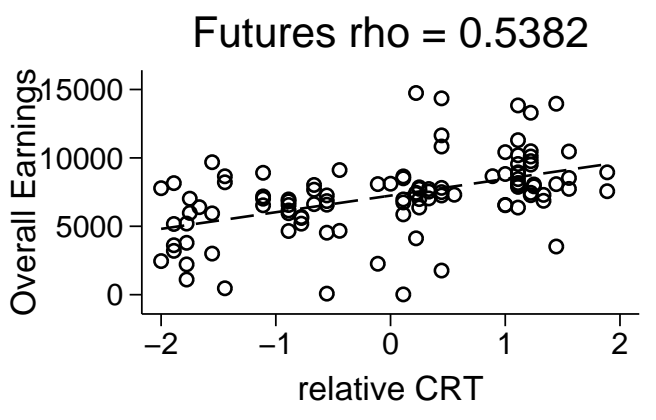

○ Earnings - - Fitted values

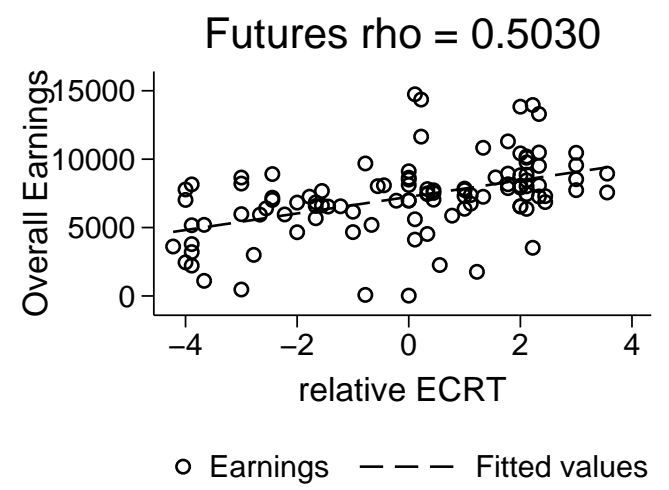

Note: all Spearman correlations with p-value $=0.0000$.

Figure 9: The (E)CRT score and final profit (in francs) in Baseline (left panels) and Futures treatment (right panels).

200 francs and a sale in the spot market for 300 francs, believing that he is making a profit of 100. However, because the fundamental value is 360 and the rational expectations price in the futures market is 24 , the individual is actually losing money in both markets. This trader myopically considers market prices without taking into account the timing of the transfer of the asset, which is a crucial determinant of the asset's value.

We might expect those with relatively low CRT and ECRT scores to be net buyers (total purchases minus total sales) in the futures market. Table 5 summarizes our findings. For both ECRT and CRT measures, we find that the more sophisticated a subject is, the less the quantity she buys in the futures market. The net amount of assets bought is significantly negatively correlated with (E)CRT scores at individual level. The ECRT score introduced 
Table 5: (E)CRT Scores and Trading Behaviors in the Futures Market

\begin{tabular}{|c|c|c|c|}
\hline & Net Purchases & Total Sales & Total Purchases \\
\hline Relative ECRT & $-0.4135^{* * *}$ & $0.1860^{*}$ & $-0.1990^{* *}$ \\
\hline Relative CRT & $-0.3980^{* * *}$ & 0.1599 & $-0.2048^{* *}$ \\
\hline
\end{tabular}

Note: There are 97 subjects in this analysis, excluding 8 subjects who never participated in the futures market.

* significant at $10 \% ; * *$ significant at $5 \%$; *** significant at $1 \%$.

in this paper is more strongly correlated with this type of decision error than the traditional CRT score.

\section{Conclusion}

The prevalence of price bubbles and crashes in experimental asset markets under the paradigm of Smith et al. [1988] has been well documented. We consider the effect of establishing a futures market for contracts to be realized in the last period of the life of the asset. The futures market might serve to fix expectations of spot prices in the last period and thereby dampen speculation in the spot market. Furthermore, it may direct the attention of agents to the last period, allowing them to better understand the multi-period, but finite, nature of the income stream generated by the asset. Our study builds on the previous experimental work of Porter and Smith [1.995] and Noussair and Tucker [20(06].

We find that one futures market, for contracts maturing in the last period of the life of the asset, reduces mispricing among a population prone to bubbles, while having no effect on mispricing in a group not prone to them. It results in an overall improvement in the effectiveness of the price discovery process.

We observe that the average (E)CRT score in a cohort, a statistic measuring the ability/willingness to reflect on a logical problem of members of a group, is significantly negatively correlated with bubbles in baseline sessions without a futures market. In the presence of a futures market, subjects seem to recruit different trading strategies. A higher individ- 
ual (E)CRT is associated with greater trading profit in the futures market, greater overall earnings, and fewer purchases in the futures market (such purchases are typically unprofitable). The enhanced CRT (ECRT) measure introduced in this paper seems to correlate with outcomes more strongly than the traditional CRT index, and higher ECRT scores at the individual level are strongly associated with greater earnings.

\section{References}

Antonios Antoniou and Phil Holmes. Futures trading, information and spot price volatility: evidence for the ftse-100 stock index futures contract using $\{\mathrm{GARCH}\}$. Journal of Banking E Finance, 19(1):117 - 129, 1995. ISSN 0378-4266. doi: http://dx.doi.org/10.1016/ 0378-4266(94)00059-C. URL http://wWw.sciencedirect.com/science/article/pii/ $037842669400059 \mathrm{C}$.

K Chan. A further analysis of the lead-lag relationship between the cash market and stock index futures market. Review of Financial Studies, 5(1):123-152, 1992. doi: 10.1093/rfs/ 5.1.123. URL http://rfs.oxfordjournals.org/content/5/1/123.abstract.

Charles C. Cox. Futures trading and market information. Journal of Political Economy, 84 (6):pp. 1215-1237, 1976. ISSN 00223808. URL http://www.jstor.org/stable/1831275.

Frank de Jong and Theo Nijman. High frequency analysis of lead-lag relationships between financial markets. Journal of Empirical Finance, 4:259 - 277, 1997. ISSN 0927-5398. doi: http://dx.doi.org/10.1016/S0927-5398(97)00009-1. URL http://www.sciencedirect. com/science/article/pii/S0927539897000091. High Frequency Data in Finance, Part 1.

Urs Fischbacher. z-tree: Zurich toolbox for ready-made economic experiments. Experimental Economics, 10(2):171-178, 2007. ISSN 1386-4157. doi: 10.1007/s10683-006-9159-4. 
Robert Forsythe, Thomas R. Palfrey, and Charles R. Plott. Asset valuation in an experimental market. Econometrica, 50(3):pp. 537-567, 1982. ISSN 00129682. URL http://www.jstor.org/stable/1912600.

Shane Frederick. Cognitive reflection and decision making. Journal of Economic Perspectives, 19(4):25-42, 2005. doi: 10.1257/089533005775196732. URL http://www.aeaweb.org/ articles .php?doi=10.1257/089533005775196732.

Daniel Friedman, Glenn W. Harrison, and Jon W. Salmon. The informational efficiency of experimental asset markets. Journal of Political Economy, 92(3):pp. 349-408, 1984. ISSN 00223808. URL http://www.jstor.org/stable/1837224.

Kenneth D. Garbade and William L. Silber. Price movements and price discovery in futures and cash markets. The Review of Economics and Statistics, 65(2):pp. 289-297, 1983. ISSN 00346535. URL http://www.jstor.org/stable/1924495.

Sanford Jay Grossman. The existence of futures markets, noisy rational expectations and informational externalities. Review of Economic Studies, 44(3):431-49, 1977. URL http: //www.jstor.org/stable/2296900.

Charles Noussair and Steven Tucker. Futures markets and bubble formation in experimental asset markets*. Pacific Economic Review, 11(2):167-184, 2006. ISSN 1468-0106. doi: 10.1111/j.1468-0106.2006.00308.x.

Stefan Palan. A review of bubbles and crashes in experimental asset markets. Journal of Economic Surveys, 27(3):570-588, 2013. ISSN 1467-6419. doi: 10.1111/joes.12023.

David P. Porter and Vernon L. Smith. Futures contracting and dividend uncertainty in experimental asset markets. The Journal of Business, 68(4):pp. 509-541, 1995. ISSN 00219398. URL http://www.jstor.org/stable/2353144. 
Vernon L. Smith, Gerry L. Suchanek, and Arlington W. Williams. Bubbles, crashes, and endogenous expectations in experimental spot asset markets. Econometrica, 56(5):pp. 1119-1151, 1988. ISSN 00129682.

Thomas Stöckl, Jürgen Huber, and Michael Kirchler. Bubble measures in experimental asset markets. Experimental Economics, 13(3):284-298, 2010. ISSN 1386-4157. doi: 10.1007/ s10683-010-9241-9. URL http://dx.doi.org/10.1007/s10683-010-9241-9.

Mark V. Van Boening, Arlington W. Williams, and Shawn LaMaster. Price bubbles and crashes in experimental call markets. Economics Letters, 41(2):179-185, 1993. URL http: //ideas.repec.org/a/eee/ecolet/v41y1993i2p179-185.htm1. 


\section{Appendix A: instructions for Futures Treatment Instructions for experiment}

\section{A1. General Instructions}

This is an experiment in the economics of market decision-making. The instructions are simple and if you follow them carefully and make good decisions, you might earn a considerable amount of money, which will be paid to you in cash at the end of the experiment. The experiment will consist of fifteen trading periods in which you will have the opportunity to buy and sell in a market. The currency used in the market is francs. All trading and earnings will be in terms of francs.

$$
460 \text { francs }=1 \text { euro }
$$

Your francs will be converted to euro at this rate, and you will be paid in euro by bank transfer after the experiment. The more francs you earn, the more euro you earn.

In each period, you may buy and sell units of a good called X in the Spot Market. X can be considered as an asset with a life of 15 periods, and your inventory of $\mathrm{X}$ carries over from one trading period to the next. Each unit of $\mathrm{X}$ in your inventory at the end of each trading period pays a dividend to you. The dividend paid on each unit is the same for every participant.

You will not know the exact value of the dividend per unit until the end of each trading period. The dividend is determined by chance at the end of each period by a random number generator. The dividend in each period has an equally likely chance of being $0,8,28$, or 60 . The information is provided in the table below.

$\begin{array}{lccccc}\text { Dividend } & \rightarrow & 0 & 8 & 28 & 60 \\ \text { Likelihood } & \rightarrow & 25 \% & 25 \% & 25 \% & 25 \%\end{array}$

The average dividend per period for each unit of $\mathrm{X}$ is 24 francs.

The dividend draws in each period are independent. That means that the likelihood of a particular dividend in a period is not affected by the dividend in previous periods.

\section{A2. Your Earnings}

At the beginning of the experiment, you will be given 3,600 francs in your Actual Cash inventory. Your earnings for the entire experiment are equal to your Actual Cash inventory at the end of period 15.

All dividends you receive are added to your Actual Cash inventory.

All money spent on purchases is subtracted from your Actual Cash inventory.

All money received from sales is added to your Actual Cash inventory. 
Example of earnings from dividends: if you have 6 units of $X$ at the end of period 3 and the dividend draw is 8 francs (which has a $25 \%$ chance of occurring), then your dividend earnings for period 3 are equal to 6 units $\times 8$ francs $=48$ francs.

\section{A3. Average Value Holding Table}

You can use your AVERAGE HOLDING VALUE TABLE (attached at the end of this document) to help you make decisions. It calculates the average amount of dividends you will receive if you keep a unit of X until the end of the experiment. It also describes how to calculate how much in future dividends you give up on average when you sell a share at any time. The following describes each of the columns in the table.

1. Ending Period: period 15 is the last trading period within the experiment, and thus the last period for which to receive a dividend payment. After the final dividend payment in period 15 , each unit of $X$ is worthless.

2. Current Period: the period during which the average holding value is being calculated. For example, in period 1, the numbers in the row corresponding to "Current Period 1" are in effect.

3. Number of Remaining Dividend Payments: the number of times that a dividend can be received from the current period until the final period (period 15). That is, it indicates the number of random asset payment draws remaining in the lifetime of the asset. It is calculated by taking the total number of periods, 15 , subtracting the current period number, and adding 1 , because the dividend is also paid in the current period.

4. Average Dividend Value per Period: the average amount of each dividend. As we indicated earlier, the average dividend in each period is 24 francs per unit of X.

5. Average Holding Value per Unit of Inventory: the average value of holding a unit of X for the remainder of the experiment. That is, for each unit of $\mathrm{X}$ you hold in your inventory for the remainder of the experiment, you receive on average the amount listed in column 5. The number in Average Holding Value is calculated by multiplying the Number of Remaining Dividend Payments with the Average Dividend Payment per Period.

Please have a look at the table now and make sure you understand it. The following example may help in your understanding.

Suppose for example that there are 7 periods remaining. Since the dividend paid on a unit of $\mathrm{X}$ has a $25 \%$ chance of being 0 , a $25 \%$ chance of being 8 , a $25 \%$ chance of being 28 , and a $25 \%$ chance of being 60 in any period, the dividend is on average 24 per period for each unit of $\mathrm{X}$. If you hold a unit of $\mathrm{X}$ for 7 periods, the total dividend paid on the unit over the 7 periods is on average $7 * 24=168$.

\section{A4. Market and Trading Rules}

At the beginning of the experiment, you will have an initial inventory of 10 units of $X$ and 3,600 francs. The experiment will consist of 15 periods. Each period will last 3 minutes. 
Before the Spot Market opens for the 15 periods of trading, a Futures Market for period 15 will be opened for 3 minutes. In the Futures Market, participants may make contracts to buy or sell units of $\mathrm{X}$ in the futures period (period 15). By making a contract to buy (sell) a unit of $\mathrm{X}$ in the Futures Market, you are committing to buy (sell) a unit of $\mathrm{X}$ at the agreed upon price at the beginning of market period 15. The actual trade will not take place until that time. For example if you make a contract to buy a unit of $\mathrm{X}$ for 10 francs in the Futures Market, then at the beginning of period 15 your Actual Inventory of $\mathrm{X}$ will increase by one unit and your Actual Cash will decrease by 10 francs. If you have committed to sell a unit of asset in the futures market, then you continue to receive the dividends that it pays out at the end of each period until the trade actually takes place in period 15 .

Futures Market period 15 will be open for 3 minutes prior to the opening of the Spot Market, and will remain open until the beginning of Spot Market period fifteen. After these 3 minutes, the Spot Market will be opened and the actual 15 periods during which the asset pays dividends will begin.

The screenshot below presents an example of the bidding screen. The Spot Market is on the left hand side of the screen and the Futures Market is on the right hand side. For the first 3 minutes of the experiment when only the futures market is available, the left hand side of the screen will be blank. A clock is presented in the top left corner showing the amount of time remaining within the period. The top center of the screen provides a summary of the dividend process as calculated on your Average Value Holding Table.

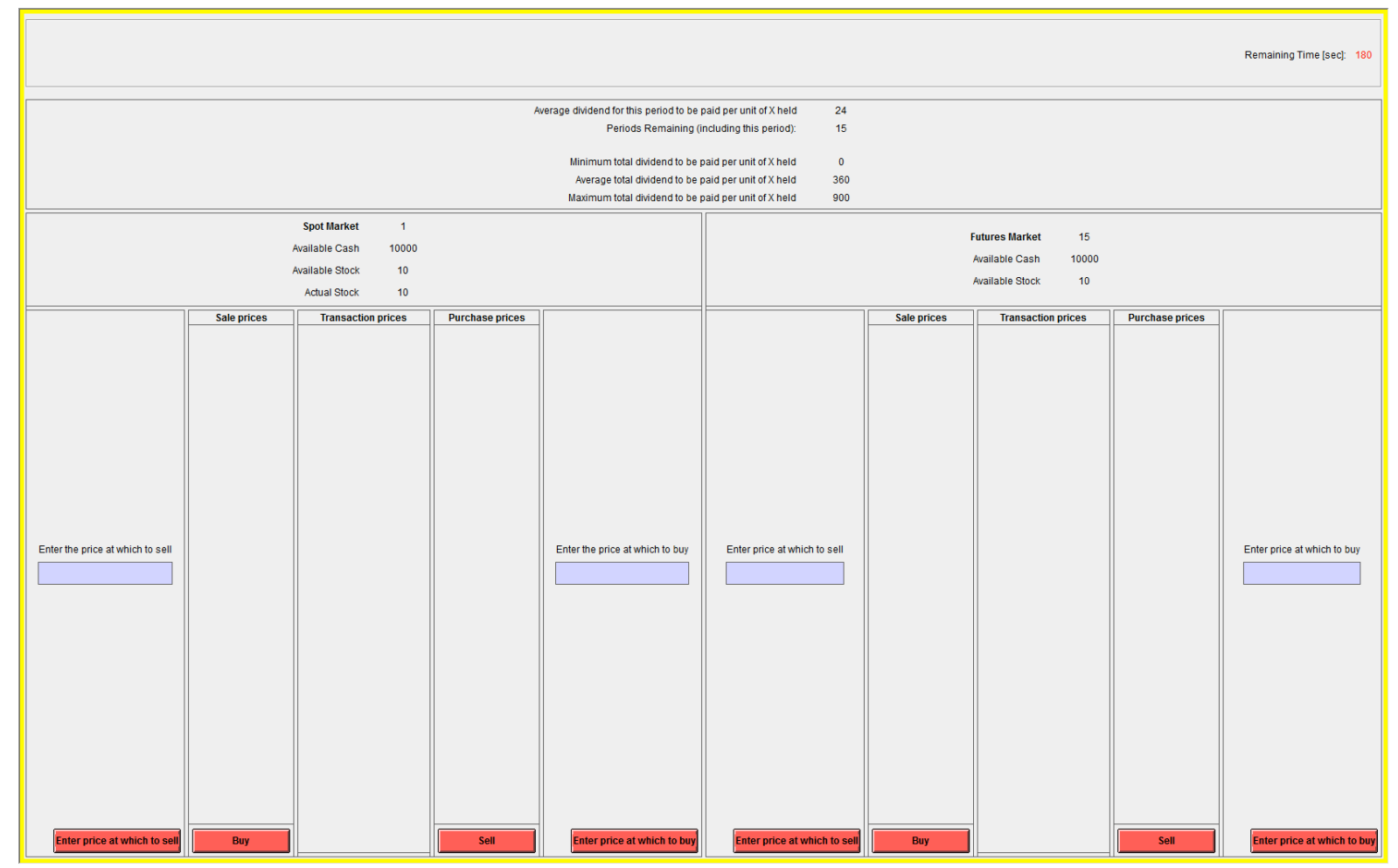

You interact within each market in the same way. If you wish to purchase a unit of X, you can do so in two ways:

1. You can submit an offer to buy, which may then be accepted by another participant that wants to sell. You do this by typing the amount you are willing to pay for a unit 
of good $\mathrm{X}$ in the box marked "Enter price at which to buy" and by pressing the corresponding button.

2. You can press the "Buy" button. This will accept the highlighted offer to sell from the "Sale Prices" column, which shows all the available offers to sell in ascending order so that the lowest price is at the top. The highlighted price is the lowest price that isn't your offer to sell.

Similarly, if you wish to sell a unit of $\mathrm{X}$, you also can do so in two ways:

1. You can submit an offer to sell, which may then be accepted by another participant that wants to buy. You do this by typing the amount you are willing to sell a unit of good $\mathrm{X}$ for in the box marked "Enter price at which to sell" and by pressing the corresponding button.

2. You can press the "Sell" button. This will accept the highlighted offer to buy from the "Purchase Prices" column, which shows all the available offers to buy in descending order so that the highest price is at the top. The highlighted price is the highest price that isn't your offer to buy.

The "Transaction prices" column shows all the prices at which a unit of X has been bought or sold in the current period.

Your offers to sell are limited by your available inventory of $\mathrm{X}$ (i.e., you cannot sell more units than you have), and your offers to buy are limited by your available cash on hand and the price (i.e., you cannot buy more than you can afford). The computer will keep track of your inventories and future contracts automatically and calculate your Available Cash (the amount of cash you have available to buy units of X) and Available Stock (the number of assets that you have available to sell) for both the Spot Market and Futures Market. In the Spot Market, you are also provided your Actual Stock (the actual number of assets you have in your inventory).

Note: The values of your Available cash and assets between markets and your Actual and Available stock within the Spot Market might differ, because if you have made a commitment to sell units of the asset in the Futures Markets, they are not available to sell, though they will remain in your inventory until the trade actually takes place at the beginning of the corresponding Spot Market period. If you have made a commitment to purchase units in the Futures Markets, the cash you have committed is not available for other purchases.

\section{Examples of how the market works.}

The numbers used in the examples are for illustrative purposes.

Example 1. Suppose that in Spot Market period 7 four traders participate in the market and:

- Trader 1 submits an offer to buy at 60

- Trader 2 submits an offer to buy at 20

- Trader 3 submits an offer to sell at 10

- Trader 4 submits an offer to sell at 40

The sale prices will be ordered in ascending order in the "Sale prices" column so that the lowest price is at the top. The first participant who presses the button "Buy" will buy the unit 
at the price of 10, if this price is highlighted in the "Sale prices" column. The purchase prices will be ordered in descending order in the "Purchase prices" so that the highest price is at the top. The first participant who presses the button "Sell" will sell at the price of 60 , if this price is highlighted in the "Purchase prices" column.

Example 2. Suppose that in Spot Market period 7 four traders participate in the market and:

- Trader 1 submits an offer to buy at 410

- Trader 2 submits an offer to buy at 400

- Trader 3 submits an offer to sell at 300

- Trader 4 submits an offer to sell at 320

The sale prices will be ordered in ascending order in the "Sale prices" column so that the lowest price is at the top. The first participant who presses the button "Buy" will buy the unit at the price of 300 , if this price is highlighted in the "Sale prices" column. The purchase prices will be ordered in descending order in the "Purchase prices" so that the highest price is at the top. The first participant who presses the button "Sell" will sell at the price of 410, if this price is highlighted in the "Purchase prices" column.

\section{A5. Summary Screen}

At the end of each period, a summary screen will be provided to you (an example of the summary screen is illustrated below).

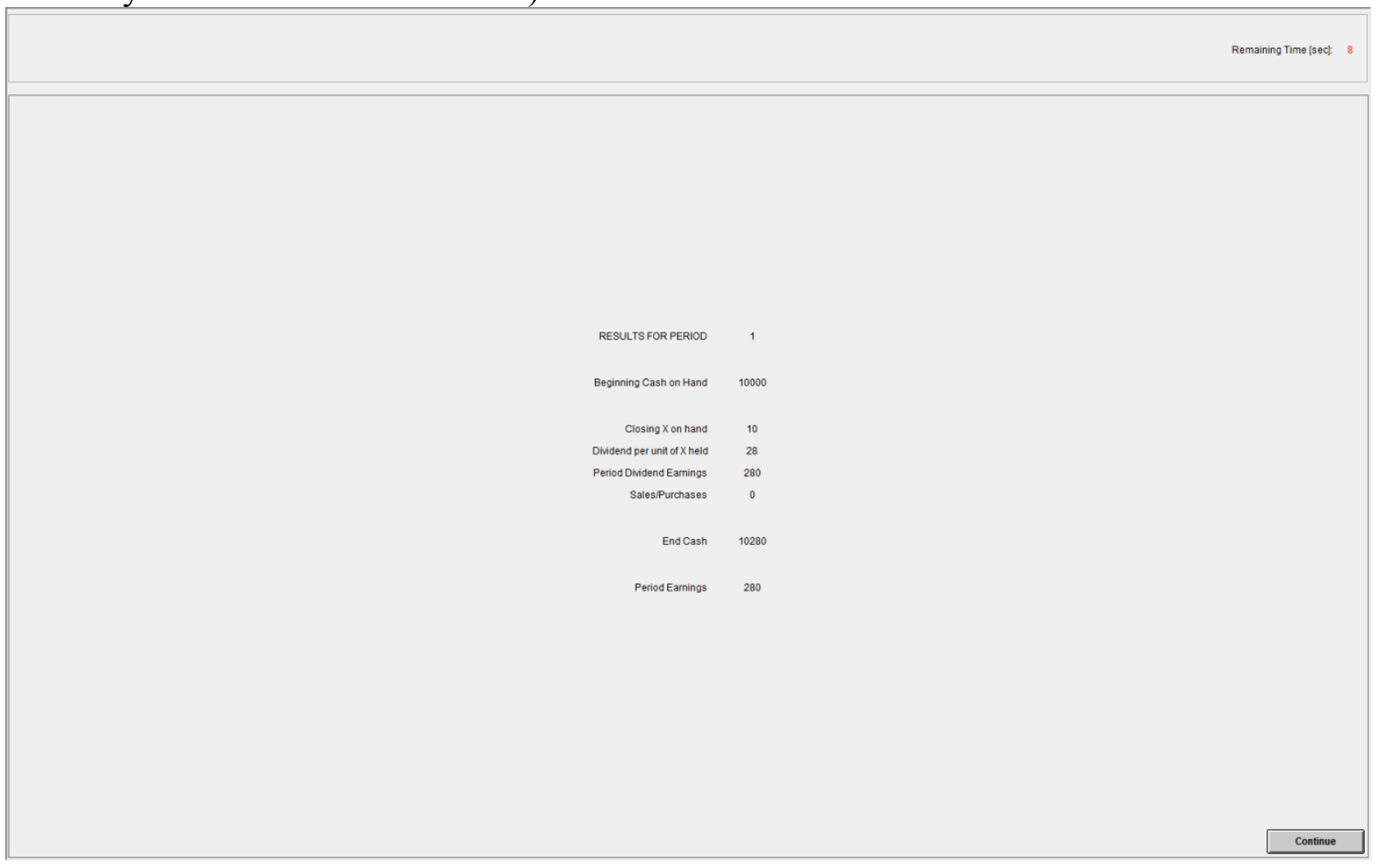

On your PERIOD EARNINGS SHEET please record the following information from the summary screen. At the beginning of period 1, record your "Beginning Cash on Hand" in column 2 in the row marked period 1. In column 3, record your earnings from 
"Sales/Purchases." Record your "Closing X on Hand" in column 4. Fill in the "Dividend per unit of X held" in column 5. Record your "Period Dividend Earnings" in column 6. In column 7, record your "End Cash" of the period. Record your "Beginning Cash on Hand" of the period in column 8. Your earnings in each period equal the difference in your End Cash minus the Beginning Cash on Hand. Record your period earnings in column 9. Repeat this procedure to obtain the period earnings of all periods.

END CASH $=$ BEGINNING CASH ON HAND + DIVIDEND PER UNIT $*$ CLOSING X ON HAND + SALES - PURCHASES

PERIOD EARNINGS = END CASH - BEGINNING CASH ON HAND

Subsequent periods should be recorded similarly. Your earnings for this experiment are given by the cash on hand at the end of period 15 .

Example of period earnings. Suppose that in period 10 your BEGINNING CASH ON HAND is 3,000 francs and your INVENTORY at the beginning of period 10 is 7 units of X. If in period 10 you sell 2 units of $X$ at a price of 200 francs and the dividend draw is 8 francs, then in period 10:

SALES $=2 * 200=400$

CLOSING X ON HAND = 7- $2=5$

PERIOD DIVIDEND EARNINGS $=$ DIVIDEND PAYMENT PER UNIT * CLOSING X ON $\mathrm{HAND}=8 * 5=40$.

END CASH $=3,000+40+2 * 200=3,440$

PERIOD EARNINGS $=$ END CASH - BEGINNING CASH ON HAND $=3,440-3,000=$ 440. 



\section{A6. Quiz}

Question 1: Suppose that you purchase a unit of X in Spot Market period 5.

a. What is the average dividend payment on the unit of $\mathrm{X}$ for Spot Market period 5?

b. If you hold that unit of $\mathrm{X}$ till the end of the experiment (11 periods including the current period), what is the average total dividend paid on the unit of $\mathrm{X}$ ?

c. What is the maximum possible dividend paid on the unit of $\mathrm{X}$ till the end of the experiment (11 periods including the current period)?

d. What is the minimum possible dividend paid on the unit of $X$ till the end of the experiment (11 periods including the current period)?

Question 2: Suppose that in Spot Market period 5 you make a commitment to buy a unit of X in the Futures Market.

a. In what period will this unit of $X$ enter your Actual Inventory?

b. In what period will you receive your first dividend payment on this unit of $X$ ?

c. What on average is the dividend payment that you will receive in that period for that unit of $X$ ?

d. What on average is the total dividend payment for that unit of $\mathrm{X}$ if you were to hold it in your inventory till the end of the experiment?

Question 3: Suppose that you have 10 units of $X$ in your Actual and Available Inventories (both in the Spot Market and Futures Market) at the beginning of Spot Market period 10, and you make a commitment to sell a unit of X in the Futures Market.

a. How many units do you have in your Actual Inventory (in the Spot Market) at the end of period 10 ?

b. How many units do you have in your Available Inventory (in the Spot Market) at the end of period 10 ?

c. What is the last period that you will receive a dividend payment on this unit of $\mathrm{X}$ ?

d. What on average is the dividend payment for this unit of $\mathrm{X}$ in that period? 


\section{AVERAGE HOLDING VALUE TABLE}

\begin{tabular}{|c|c|c|c|c|c|c|}
\hline $\begin{array}{l}\text { Ending } \\
\text { Period }\end{array}$ & $\begin{array}{l}\text { Current } \\
\text { period }\end{array}$ & $\begin{array}{c}\text { Number of } \\
\text { Holding Periods }\end{array}$ & $*$ & $\begin{array}{l}\text { Average Dividend } \\
\text { Value Per Period }\end{array}$ & $=$ & $\begin{array}{l}\text { Average Holding Value } \\
\text { Per Unit of Inventory }\end{array}$ \\
\hline 15 & 1 & 15 & $*$ & 24 & $=$ & 360 \\
\hline 15 & 2 & 14 & $*$ & 24 & $=$ & 336 \\
\hline 15 & 3 & 13 & $*$ & 24 & $=$ & 312 \\
\hline 15 & 4 & 12 & $*$ & 24 & $=$ & 288 \\
\hline 15 & 5 & 11 & $*$ & 24 & $=$ & 264 \\
\hline 15 & 6 & 10 & $*$ & 24 & $=$ & 240 \\
\hline 15 & 7 & 9 & $*$ & 24 & $=$ & 216 \\
\hline 15 & 8 & 8 & $*$ & 24 & $=$ & 192 \\
\hline 15 & 9 & 7 & $*$ & 24 & $=$ & 168 \\
\hline 15 & 10 & 6 & $*$ & 24 & $=$ & 144 \\
\hline 15 & 11 & 5 & $*$ & 24 & $=$ & 120 \\
\hline 15 & 12 & 4 & $*$ & 24 & $=$ & 96 \\
\hline 15 & 13 & 3 & $*$ & 24 & $=$ & 72 \\
\hline 15 & 14 & 2 & $*$ & 24 & $=$ & 48 \\
\hline 15 & 15 & 1 & $*$ & 24 & $=$ & 24 \\
\hline
\end{tabular}


PERIOD EARNINGS SHEET

\begin{tabular}{|c|c|c|c|c|c|c|c|c|}
\hline $\begin{array}{c}\text { (1) } \\
\text { PERIOD }\end{array}$ & $\begin{array}{c}\text { (2) } \\
\text { BEGINNING } \\
\text { CASH }\end{array}$ & $\begin{array}{c}\text { (3) } \\
\text { SALES/ } \\
\text { PURCHASES }\end{array}$ & $\begin{array}{c}\text { (4) } \\
\text { CLOSING X ON HAND }\end{array}$ & $\begin{array}{c}(5) \\
\text { DIVIDEND } \\
\text { PER UNIT }\end{array}$ & $\begin{array}{c}(6) \\
\text { PERIOD DIVIDEND } \\
\text { EARNINGS }\end{array}$ & $\begin{array}{c}(7) \\
\text { END CASH }\end{array}$ & $\begin{array}{c}(8) \\
\text { BEGINNING } \\
\text { CASH }\end{array}$ & $\begin{array}{c}\text { (9) } \\
\text { PERIOD } \\
\text { EARNINGS }\end{array}$ \\
\hline 1 & 3,600 & & & & & & 3,600 & \\
\hline 2 & & & & & & & & \\
\hline 3 & & & & & & & & \\
\hline 4 & & & & & & & & \\
\hline 5 & & & & & & & & \\
\hline 6 & & & & & & & & \\
\hline 7 & & & & & & & & \\
\hline 8 & & & & & & & & \\
\hline 9 & & & & & & & & \\
\hline 10 & & & & & & & & \\
\hline 11 & & & & & & & & \\
\hline 12 & & & & & & & & \\
\hline 13 & & & & & & & & \\
\hline 14 & & & & & & & & \\
\hline 15 & & & & & & & & \\
\hline
\end{tabular}




\section{Appendix B: CRT Questions}

Please answer the questions outlined below.

For every correct answer, you will receive $€ 1$ at the end of the experiment.

1. A bat and a ball cost $€ 1.10$ in total. The bat costs $€ 1.00$ more than the ball. How much does the ball cost in cents?

2. If it takes 5 machines 5 minutes to make 5 widgets, how long would it take 100 machines to make 100 widgets?

3. In a lake, there is a patch of lily pads. Every day, the patch doubles in size. If it takes 48 days for the patch to cover the entire lake, how long (in days) would it take for the patch to cover half the lake? 